\title{
REVIEW
}

\section{Lipodystrophy: metabolic insights from a rare disorder}

\author{
Isabel Huang-Doran ${ }^{\mathbf{1}}$, Alison Sleigh², Justin J Rochford ${ }^{\mathbf{1}}$, Stephen $\mathbf{O}^{\prime}$ Rahilly $^{\mathbf{1}}$ and David B Savage ${ }^{\mathbf{1}}$ \\ ${ }^{1}$ Metabolic Research Laboratories, Institute of Metabolic Science and ${ }^{2}$ Wolfson Brain Imaging Centre, Addenbrooke's Hospital, University of Cambridge, \\ Hills Road, Cambridge CB2 0QQ, UK \\ (Correspondence should be addressed to D B Savage; Email: dbs23@medschl.cam.ac.uk)
}

\begin{abstract}
Obesity, insulin resistance and their attendant complications are among the leading causes of morbidity and premature mortality today, yet we are only in the early stages of understanding the molecular pathogenesis of these aberrant phenotypes. A powerful approach has been the study of rare patients with monogenic syndromes that manifest as extreme phenotypes. For example, there are striking similarities between the biochemical and clinical profiles of individuals with excess fat (obesity) and those with an abnormal paucity of fat (lipodystrophy), including severe insulin resistance, dyslipidaemia, hepatic steatosis and
\end{abstract}

features of hyperandrogenism. Rare lipodystrophy patients therefore provide a tractable genetically defined model for the study of a prevalent human disease phenotype. Indeed, as we review herein, detailed study of these syndromes is beginning to yield valuable insights into the molecular genetics underlying different forms of lipodystrophy, the essential components of normal adipose tissue development and the mechanisms by which disturbances in adipose tissue function can lead to almost all the features of the metabolic syndrome.

Journal of Endocrinology (2010) 207, 245-255

\section{Introduction}

Insulin resistance is implicated in a vast burden of premature morbidity and mortality. Through its consistent association at the population level with diabetes mellitus and its complications, fatty liver disease and the polycystic ovarian syndrome (PCOS; with its attendant affects on female fertility), insulin resistance is arguably one of the greatest current threats to human health today. Intensive efforts are therefore underway to understand the genetic and molecular mechanisms underlying this prevalent phenotype. It is well established that obesity is a key player in the pathogenesis of most forms of insulin resistance, interacting with a polygenic diathesis. Despite intensive efforts, however, the molecular mechanisms underlying the relationship between obesity, insulin resistance and metabolic disease are incompletely understood, and the contributory genes are poorly defined.

A powerful approach to this daunting problem - and one that is potentially applicable to any complex trait - is to identify and study the most extreme end of the phenotypic spectrum; that is, in our case, patients with severe insulin resistance. Such patients typically have either profound compensatory hyperinsulinaemia (with fasting levels above $150 \mathrm{pM}$ and post-prandial levels above $1500 \mathrm{pM}$ ) or diabetes that requires high levels (over 200 units per day) of exogenous insulin for glycaemic control. Other clinical features that are characteristic of severe insulin resistance include acanthosis nigricans, the dark velvety thickening of the skin typically most obvious in body flexures and features of hyperandrogenism in girls. These syndromes are largely attributable to rare, inherited mutations in single genes, leading either to defects in canonical insulin signalling (either the insulin receptor itself or downstream components of the insulin signalling cascade) or to lipodystrophy, where the primary defect is a paucity of adipose tissue (Savage et al. 2007b, Semple et al. 2010).

Owing to the severity of insulin resistance in these rare syndromes, their attendant physiological perturbations and pathological consequences are particularly overt. Moreover, their monogenic aetiology enables inference of firmer causeeffect relationships. In recent years, the study of patients with severe insulin resistance - particularly those with lipodystrophy - in combination with murine and in vitro cellular models has highlighted the potential insights to be gained from patients with rare syndromes. Here, we briefly summarise the lipodystrophy syndromes, their presentation and their classification, then we review recent work into the causes and effects of lipodystrophy, and how the insights they provide may be applicable to prevalent metabolic disease. 
is frequently bad enough to lead to eruptive xanthomata and pancreatitis. Splenomegaly is common. Serum adiponectin, sex hormone-binding globulin and insulin-like growth factor binding protein 1 are typically suppressed and can be useful in discriminating lipodystrophy syndromes from those resulting from insulin receptor defects, which can also feature a paucity of fat tissue (Semple et al. 2006, 2007, 2008).

Partial lipodystrophies are characterised by abnormal fat topography along with an overall reduction in fat mass, although occasionally total adipose tissue levels are normal. The familial partial lipodystrophy (FPLD) syndromes are milder, autosomal dominant syndromes that may not be prominent until puberty (Garg 2004). The predominant effect is usually on the limb and gluteal fat depots with variable truncal involvement and normal or excess fat on the face and neck. FPLD is more obvious in women as a result of the fact that women normally have significantly more femorogluteal fat than men, and women are also typically more severely affected, often presenting with features of hyperandrogenism. Partial lipodystrophy is particularly difficult to recognise clinically in lean men. Acanthosis nigricans is common, and metabolic features range from asymptomatic impaired glucose tolerance with mild dyslipidaemia to severe insulin resistance, diabetes and profound dyslipidaemia, depending on the extent of fat tissue loss. Non-alcoholic steatohepatitis is a common complication, as is cardiovascular disease. The most common form of partial lipodystrophy is associated with the use of antiretroviral therapy in patients with human immunodeficiency virus (HIV) infection (Tershakovec et al. 2004); acquired lipodystrophy may also occur as a component of autoimmune syndromes, involving immune-mediated premature destruction of adipocytes (Seip \& Trygstad 1996, Misra et al. 2004).

\section{Molecular genetics of lipodystrophy}

Over the past two decades, a combination of linkage analysis and candidate gene screening has led to the identification of nine genes associated with congenital lipodystrophy, either generalised or partial (summarised in Table 1). The observation that the loss of function of these genes leads to lipodystrophy is in itself powerful, illustrating that the encoded protein is essential for normal fat tissue development and/or function in humans and, more distally, for human metabolic health. Such a statement could not be made so convincingly from in vitro studies or mouse models alone, although identification of these proteins as essential mediators of adipose tissue function lends further support to the studies of their actions in appropriate model systems. Conversely, our understanding of adipocyte biology has informed candidate gene screens in patients with lipodystrophy of unknown cause, and has in some cases led to the identification of genes that would not otherwise have emerged. Despite this progress, many patients with clinical diagnoses of lipodystrophy carry no mutations in known genes, suggesting that other causative genes are at play, which have yet to be identified. Thus, based on what is currently known, it is possible to functionally categorise genes implicated in the pathogenesis of lipodystrophy as being primarily involved in i) the transcriptional regulation of adipocyte differentiation, ii) substrate (particularly fatty acid) uptake by adipocytes, iii) triacylglycerol (TAG) synthesis or iv) lipid droplet formation.

\section{Induction of adipogenic gene expression}

Adipocytes are believed to originate from pluripotent mesenchymal stem cells via committed precursors known as pre-adipocytes (Lane \& Tang 2005). The differentiation of fibroblast-like pre-adipocytes into mature adipocytes in which a large unilocular lipid droplet occupies most of the cell volume is referred to as adipogenesis. The studies of in vitro models of adipogenesis reveal a precise pattern of gene up- and/or downregulation leading ultimately to the expression of mature adipocyte genes (Rosen et al. 2000). Defects in certain key genes would therefore be expected to disrupt adipogenesis and lead to a lipodystrophic phenotype. To date, the clearest example of this mechanism is the form of FPLD associated with dominant loss-of-function mutations in PPARG (referred to as FPLD3) (Savage et al. 2003, Agostini et al. 2006). PPAR $\gamma$ is a member of the nuclear hormone receptor superfamily and is highly expressed in adipose tissue, monocytes/macrophages, colon and at lower levels in multiple other tissues (Desvergne \& Wahli 1999). It plays a critical role in adipocyte differentiation and is often dubbed the 'master regulator' (Spiegelman 1998). In spite of its established role in adipogenesis however, which is to an extent confirmed by its association with lipodystrophy, defects in PPAR $\gamma$ cause only a partial form of the disease. It remains to be explained why the pattern of fat loss is regional, and why some depots are spared and not others.

Mutations in BSCL2, encoding the protein BSCL2 or seipin, account for many cases of CGL (Magre et al. 2001). BSCL2 was originally identified as a lipodystrophy gene through a linkage analysis approach. BSCL2 is a protein of unknown function that localises to the endoplasmic reticulum (ER; Agarwal \& Garg 2004, Szymanski et al. 2007). Although initially reported to be most highly expressed in the brain, it is also highly expressed in adipocytes (Magre et al. 2001, Payne et al. 2008). Several studies have suggested that BSCL2 may be involved in lipid droplet formation and is localised at points of contact between nascent lipid droplets and the ER membrane; however, its precise involvement in this process remains to be elucidated (Szymanski et al. 2007, Fei et al. 2008, Boutet et al. 2009). Patients with lipodystrophy resulting from BSCL2 mutations are difficult to reliably distinguish from AGPAT2 mutations (below) on clinical grounds alone, although the loss of adipose tissue from mechanical fat pads such as the palms, soles, orbits, scalp and periarticular regions may be specific to BSCL2 mutations and may indicate a distinct pathological mechanism (Simha \& Garg 2003). Recent data also suggest that adiponectin levels are higher in CGL patients with BSCL2 mutations than in those with AGPAT2 mutations 
(Antuna Puente et al. 2010). Whatever its action within the adipocyte, BSCL2 clearly plays a pivotal role in adipose tissue function, one that would have been far more elusive without the striking phenotypes of CGL patients.

Autosomal dominant mutations in $L M N A$, encoding lamin A/C, cause Dunnigan-type familial partial lipodystrophy (FPLD2; Cao \& Hegele 2000, Shackleton et al. 2000, Speckman et al. 2000). This is the most commonly identified mutation in lipodystrophic patients. Children are born with an apparently normal fat distribution but typically manifest clinically discernible limb and truncal lipodystrophy with the onset of puberty (when fat depots normally expand). Fat around the head and neck, and visceral fat are typically spared. Lamin $\mathrm{A} / \mathrm{C}$ is a nuclear envelope protein expressed in all cell types (Dechat et al. 2008). Initial studies suggest that $L M N A$ mutations are associated with impaired adipogenesis, and molecular studies have implicated the key adipogenic transcription factor SREBP1c (Kim \& Spiegelman 1996, Lloyd et al. 2002, Wojtanik et al. 2009). SREBP1c was found to bind lamin $\mathrm{A} / \mathrm{C}$, and $L M N A$ mutations have been variously reported to cause the loss of SREBP1c binding or the sequestration, inhibition or mislocalisation of SREBP1c depending on the mutation or experimental system involved (Lloyd et al. 2002, Capanni et al. 2003, 2005, Boguslavsky et al. 2006). Overall, the molecular mechanism underlying the loss of adipose tissue in these individuals is unclear. Similarly, why only selective adipose depots are consistently affected remains unexplained. It is now clear that lamin proteins have many cellular roles including chromatin and transcription factor binding and organisation of the nuclear membrane and cytoskeleton (Dechat et al. 2008). This suggests that lamin A/C mutations will affect multiple pathways in developing adipocytes, and this may underlie the varied influences in different adipose depots and other tissues. Interestingly, mutations of the gene ZMPSTE24, encoding a metalloproteinase essential for the processing of prelamin A to the mature lamin A protein, can also cause a syndrome of partial lipodystrophy with mandibuloacral dysplasia (MAD; Agarwal et al. 2003). While it is currently unclear, the molecular mechanisms involved are evidently likely to significantly overlap those of $L M N A$ mutations. Also of note is the association of $L M N A$ mutations with a further set of rare familial syndromes including cardiac conduction disease syndrome, some forms of muscular dystrophy and Werner syndrome, MAD, various progeroid syndromes and CharcotMarie-Tooth syndrome (Worman \& Bonne 2007). Some mutations in the $L M N A$ gene are consistently associated with tissue-specific phenotypes, whereas others appear to cause 'overlap syndromes' in which patients manifest 'dystrophies' of more than one tissue type.

Finally, mutations in $A K T 2$ cause severe insulin resistance in association with lipodystrophy, highlighting the importance of post-receptor insulin signalling in adipose tissue formation (George et al. 2004). Insulin is a key component of the cocktail used to induce adipogenesis in almost all cellular adipocyte models (e.g. 3T3-L1 adipocytes) and is also involved in stimulating glucose uptake into adipocytes, so impaired insulin signalling could conceivably lead to lipodystrophy as a result of impaired adipogenesis and/or limited substrate availability (Saltiel \& Kahn 2001).

\section{Substrate availability}

A single patient with generalised lipodystrophy and short stature has been identified with a homozygous loss-of-function mutation in CAV1, encoding caveolin-1, one of a number of proteins mediating caveola formation (Cao et al. 2008, Kim et al. 2008). Caveolae are specialised plasma membrane microdomains involved in fatty acid uptake, insulin receptor recycling and GLUT4 organisation in adipocytes (Schlegel et al. 1998). It is therefore to be expected that the loss of this protein should disrupt adipose tissue function, both through impairments in fatty acid uptake, and thus TAG synthesis, and (more speculatively) through the loss of insulin signalling into the cell (Cohen et al. 2003, Saltiel \& Pessin 2003). In addition, mutations in PTRF (encoding polymerase 1 and transcript release factor, also known as cavin-1) have recently been identified in several kindreds with an autosomal recessive disorder characterised by generalised lipodystrophy and muscular dystrophy (Liu et al. 2008, Hayashi et al. 2009). Unlike BSCL2 and AGPAT2 mutations, in which somatic overgrowth is a common feature, CAV1 defects were associated with short stature (albeit in a single kindred so far). PTRF is another abundant caveolar protein, which appears to stabilise the expression of caveolin, a previous finding that led to its ultimate identification as a causative gene in lipodystrophy (Hill et al. 2008, Liu \& Pilch 2008). These findings indicate that specialised machinery for efficient uptake of fatty acid substrates into adipocytes is essential for normal metabolic health.

\section{TAG synthesis}

A large subset of patients with congenial generalised lipodystrophy harbour biallelic mutations in AGPAT2, encoding the enzyme acylglycerol-3-phosphate O-acyltransferase 2 (AGPAT2) initially identified as a cause of generalised lipodystrophy by positional cloning (Agarwal et al. 2002). Indeed, collectively, mutations in AGPAT2 and BSCL2 account for over $95 \%$ of cases of CGL. This acyltransferase enzyme, located in the ER, catalyses the conversion of lysophosphatidic acid to phosphatidic acid, a key step in the synthesis of triglycerides and glycerophospholipids from glycerol-3-phosphate. In vitro enzyme assays have confirmed that the majority of known human AGPAT2 mutants were associated with a marked reduction in enzymatic activity (Haque et al. 2005). The failure of TAG synthesis therefore provides a very plausible explanation for lipodystrophy in patients with genetic defects in the AGPAT2 gene. However, cellular studies have also demonstrated that disruption of AGPAT2 or BSCL2 inhibits not only lipid synthesis but also the normal induction of adipogenic gene expression during fat cell development (Gale et al. 2006, Payne et al. 2008). This may reflect the tight 
co-regulation of gene expression and lipid droplet formation in developing adipocytes or indicate that these proteins possess functions in addition to their proposed roles in lipogenesis.

\section{Lipid droplet assembly}

Central to the adipocyte's role as a fat storage organ is the ability to store lipid species in an inert form within the cell as a large, unilocular lipid droplet. Recently, a homozygous mutation in CIDEC, encoding a lipid droplet-associated protein, was identified in a patient with partial lipodystrophy, insulin resistance and diabetes (Puri et al. 2007, Rubio-Cabezas et al. 2009). Histological assessment of biopsies of residual fat depots indicated the presence of multilocular lipid droplets. A particularly striking element of the patient's phenotype was recurrent diabetic ketoacidosis, which is very unusual in patients with acanthosis nigricans and elevated C-peptide levels. The fact that both plasma fatty acid and urinary glycerol levels were elevated suggests that this may have been a consequence of impaired lipolytic regulation. Cidec null mice manifest similar reductions in overall fat mass, white adipocytes with multilocular lipid droplets and apparently accelerated lipolysis (Nishino et al. 2008). Interestingly, however, the lipolytically released fatty acids appear to be preferentially oxidised within the adipocytes, so plasma fatty acid levels were not elevated in these mice and insulin sensitivity was preserved or even improved. Further work will be required to resolve these intriguing interspecies differences.

\section{Adipose tissue and metabolic health}

In addition to lending insights into the molecular requirements of adipose tissue development, the study of lipodystrophy has also informed our understanding of the role of fat in human metabolic health, both by clearly illustrating in an unambiguous way the profound consequences of lack of adipose tissue, and by providing human models in which to study the mechanisms by which they arise.

\section{Adipose tissue as a key mediator of metabolic health}

Although cautions are rife as to the dangers of excess adipose tissue, the metabolic ill health suffered by patients who wholly or partially lack adipose tissue clearly illustrates that possession of healthy fat depots is an essential requirement for the maintenance of metabolic homeostasis. More than merely storing excess lipid, adipose tissue crucially stores energy in a metabolically 'safe' form. In addition, adipose tissue acts as a dynamic buffer for post-prandial lipid fluxes (Frayn 2002) and is also a key endocrine organ, synthesising and secreting hormones and adipokines, most notably leptin and adiponectin (Kershaw \& Flier 2004). As such, lipodystrophy patients have contributed to a shift in the current thinking about metabolic disease from a 'glucocentric' towards a more 'lipocentric' view, with fat perceived as an organ essential for the maintenance of metabolic homeostasis in the context of a tide of excess calories.

Despite the obvious detrimental effects of excess adiposity on metabolic health, the striking resemblance in biochemical and clinical features of lipodystrophic patients to the morbidly obese illustrates that the relationship between metabolic health and fat mass is a complex one. Consistently, a subset of patients with extremely high body mass index appear nonetheless protected from metabolic disease, the so-called 'metabolically healthy obese' (Bluher 2009). Based on these observations of both common and rare, extreme human disease, an 'adipose expandability' model of metabolic disease has been proposed (Virtue \& Vidal-Puig 2008). Here, the underlying assumption is that human adipose tissue has a limited capacity to expand, through a combination of adipocyte hyperplasia (although this is limited in adults) and hypertrophy (Spalding et al. 2008). States of positive energy balance are associated with expansion of fat depots to accommodate the excess energy intake, while in states of negative energy balance, the energy stored within fat is mobilised, with subsequent shrinkage in adipose fat mass. However, this expandability is finite and can only occur up to a particular set point which varies on an individualto-individual basis and which may be genetically determined. Beyond this set point, additional excess energy cannot be accommodated in an appropriate way and, with sustained positive energy balance, adipocytes become hypertrophic and begin to fail. Oxidative and ER stress within the adipocyte, infiltration of macrophages, release of inflammatory cytokines and dysregulation of adipose tissue's normal endocrine role, with impaired production of leptin and adiponectin, follow (de Ferranti \& Mozaffarian 2008). This represents unhealthy, stressed adipose tissue. In such states, altered lipolytic regulation, along with the dysregulated hormone and cytokine production, leads to 'lipotoxicity' in other peripheral tissues. As a consequence of the inability of adipose tissue to accommodate surplus energy as fat, fat tends to accumulate in other organs, where it is frequently termed 'ectopic fat'. This ectopic fat accumulation probably affects many organs in the body but is most clearly associated with metabolic abnormalities in the liver, skeletal muscle and more recently the pancreas. Through various molecular mechanisms that are only beginning to be elucidated, insulin resistance is then induced in these tissues (Savage et al. 2007a, Poitout \& Robertson 2008, Erion \& Shulman 2010, Samuel et al. 2010).

Based on this model, then, is the proposition that metabolic health is determined by adipocyte expandability (i.e. position of the set point) rather than absolute fat mass (Danforth 2000, Virtue \& Vidal-Puig 2008). Individuals with morbid obesity have a normal or high capacity for fat expandability, but, due to the persistently high caloric loads, this capacity is ultimately exceeded and adipose tissue dysfunction ensues. In contrast, individuals with lipodystrophy have a very low set point, which is exceeded in virtually all circumstances, leading to metabolic dysregulation that occurs sooner, earlier and more 
severely. In many cases, residual adipose tissue in patients with lipodystrophy is likely to be dysfunctional. This is a very different state from lean individuals who possess numerous, healthy but 'empty' adipocytes that can be readily filled if necessary without compromising adipocyte function. Consistently, mouse strains in which this set point is deliberately lowered show a very similar metabolic picture. An example is the A-ZIP/F-1 transgenic mouse model in which mice express a dominant negative protein that heterodimerises with and inactivates members of the $\mathrm{C} / \mathrm{EBP}$ and JUN families of B-ZIP transcription factors leading to generalised lipodystrophy (Moitra et al. 1998). More direct evidence for the need to be able to expand adipose tissue depots in response to sustained positive energy balance comes from the PPARG P465L mouse model. The equivalent human variant is associated with partial lipodystrophy (FPLD3) and severe insulin resistance, but the P465L knockin mice do not manifest insulin resistance unless crossed with severely hyperphagic leptin-deficient ob/ob mice (Gray et al. 2006). In the latter context, namely persistent hyperphagia due to the absence of an essential appetite-regulating hormone (leptin), the defect in adipogenesis and adipocyte function induced by the mutation leads to profound metabolic disturbances and severe early onset diabetes. This model is further supported by transgenic mice overexpressing adiponectin, another adipocyte-derived protein (adipokine) with a putative insulin-sensitising action. When crossed with ob/ob mice, these mice become even more obese than standard $\mathrm{ob} / \mathrm{ob}$ mice and yet manifest significantly improved metabolic homeostasis, suggesting that if adipose tissue can expand to accommodate surplus calories, insulin resistance can be ameliorated (Kim et al. 2007).

Despite a growing list of genes underlying a predisposition to adiposity (i.e. absolute fat mass), the determinants of this set point (i.e. adipose expandability) are unclear, although it is reasonable to suspect that those genes underlying monogenic lipodystrophy, or other related ones, may be contributory. Focused examination of lipodystrophy and 'metabolically healthy obese' patients may soon reveal insights into this important issue.

Multiple further lines of evidence, both in humans and in murine models, lend support to the adipose expandability hypothesis. One of the most effective and important components of management of lipodystrophy is caloric restriction, in order to minimise the stress imparted on limited or absent fat depots that are already sick and failing (Robbins et al. 1979). The low levels of leptin production worsen the situation by precipitating hyperphagia, which is often extreme. Leptin replacement should therefore always be considered in patients with generalised lipodystrophy, and has been shown to have sustained beneficial metabolic effects (Chong et al. 2009).

An alternative strategy to relieving metabolic stress on diseased adipose tissue would be to provide extra fat depots. Clearly in humans, the prospect of fat transplantation is still a distant one; nevertheless, transplantation of fat depots into mouse models of lipodystrophy (e.g. AZIP), which also show the characteristic signature of metabolic disease (hypertriglyceridaemia, low high-density lipoprotein (HDL), fatty liver, etc.), caused a significant amelioration of metabolic health (Gavrilova et al. 2000). Subsequent studies, however, have suggested that transplantation of adipose tissue lacking leptin was unable to reverse the metabolic phenotype associated with lipodystrophy, emphasising the need for both increased 'adipose storage capacity' and a brake on ongoing excess energy intake (Colombo et al. 2002, Sennello et al. 2006).

A more conservative alternative to fat transplantation in humans is the use of thiazolidinediones (PPARG agonists), commonly used as insulin-sensitising agents in the treatment of diabetes. Insulin sensitisation occurs despite consistent and substantial weight gain associated with use of thiazolidinediones, probably due at least in part to the stimulation of adipogenesis (although fluid retention also contributes to weight gain in this setting). Curiously, these drugs appear to worsen hepatic steatosis in murine lipodystrophy models (Kim et al. 2003), raising concerns about their utility in this scenario.

\section{Visceral versus subcutaneous fat}

A striking feature of the lipodystrophy syndromes is the clinical heterogeneity, particularly with respect to the size and site of adipose tissue loss, yet the consistency of the metabolic defect. Whereas adipose tissue is globally absent in patients with generalised lipodystrophy, this loss is more restricted in partial lipodystrophy and, importantly, often associated with compensatory increases in the size of other fat depots, with an increase in overall adiposity in some cases (Fig. 1). With very few exceptions, however, lipodystrophy is associated with impaired insulin sensitivity and dyslipidaemia. One such exception is the form of acquired partial lipodystrophy commonly associated with the presence of an $\operatorname{IgG}$ autoantibody which stabilises C3 (complement component C3) convertase leading to low C3 complement levels (Sissons et al. 1976). This so-called 'nephritic factor' is also associated with glomerular disease (typically mesangiocapillary glomerulonephritis type II (Williams 1997)). The lipodystrophy associated with C3 nephritic factor almost always develops in a cephalocaudal direction with the loss of facial and upper limb fat preceding variable trunk fat loss. In our experience, people with this form of lipodystrophy only become insulin resistant and manifest other features of the metabolic syndrome when upper body fat loss becomes more extensive and/or when the patient develops relative lower body adiposity. Presumably, either or both of these states lead to lipid stores exceeding the bodies' capacity to accommodate them in healthy adipose depots. These observations highlight the fact that all fat depots are not equal and that some are more strongly associated with metabolic health than others. Specifically, the accumulation of fat around abdominal viscera and inside intra-abdominal organs is strongly associated with obesity-related complications including type 2 diabetes 

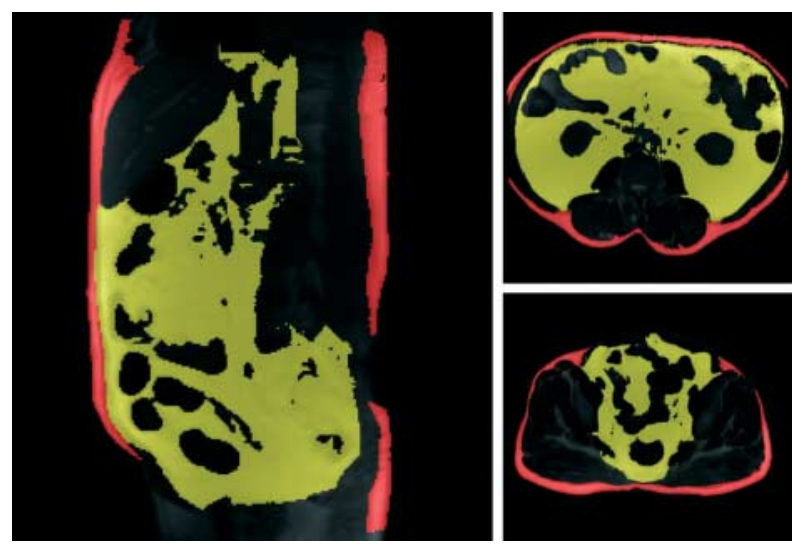

Figure 1 Fat distribution in a patient with familial partial lipodystrophy (FPLD) due to a heterozygous R482W LMNA mutation. Note the striking paucity of subcutaneous fat (highlighted in red) and abundant visceral fat (highlighted in yellow). The image on the left is a sagittal T1-weighted MRI image, whereas those on the right are transverse abdominal (upper right panel) and gluteal (lower right panel) images.

mellitus and accelerated coronary artery disease (Snijder et al. 2004), and indeed it is the subcutaneous fat depots in the limbs and gluteal regions that are invariably lost in congenital lipodystrophy syndromes, often with compensatory upregulation of the metabolically more 'dangerous' visceral fat.

The reason for differences in adipose depots is unclear, but at least one contributing element may be the fact that venous blood from visceral adipose tissue drains into the portal vein and then directly into the liver. Non-esterified fatty acids (NEFAs) and adipokines released into the circulation from visceral adipocytes tend to have a more dramatic impact on hepatic metabolism as a consequence of this intimate anatomical association. However, there is also evidence for cell-intrinsic differences between the different fat depots (Gesta et al. 2006), with different patterns of gene expression in fat sampled from different regions. Visceral depots produce more proinflammatory cytokines including TNF $\alpha$ and IL6, and less adiponectin. Indeed, transplantation of subcutaneous fat into the abdominal cavity improved the metabolic profile of mice, while visceral-to-visceral or visceral-to-subcutaneous transplantation had little effect, providing further evidence in favour of subcutaneous fat depots being essential for metabolic homeostasis (Tran et al. 2008).

\section{Free fatty acid turnover/flux}

Early severe insulin resistance in children with PPARG mutation-associated lipodystrophy highlights the essential role of PPAR $\gamma$ in insulin action. This is probably primarily through effects on adipogenesis, but also through a major functional defect in residual adipose tissue. In addition to its role as an 'energy storage depot', adipose tissue also plays a vital dynamic role in buffering the post-prandial nutrient/ lipid influx. Detailed in vivo functional studies of abdominal subcutaneous adipose tissue in a patient with a dominant negative PPARG mutation involving the measurement of arteriovenous fluxes across this fat depot revealed dramatic defects in adipose tissue metabolic flux control (Savage et al. 2003, Tan et al. 2008). For example, the usual increase in postprandial triglyceride clearance was essentially absent in this patient, and dynamic changes in adipose tissue lipolysis appeared to be absent. NEFA output was thus low during an overnight fast but sustained following meal ingestion. This inability to trap and store NEFAs post-prandially is likely to expose skeletal muscle and liver to NEFAs in an unregulated manner, with consequent effects on insulin sensitivity.

\section{Pathogenesis of hepatic steatosis}

Insulin resistance is causally associated with some of the leading worldwide causes of morbidity, but it remains to be determined precisely how it leads to diseases as seemingly diverse as fatty liver, atherosclerosis and PCOS. At the simplest level, it is unclear whether insulin resistance is inherently damaging (and if so how), whether it is the compensatory hyperinsulinaemia that is pathogenic or whether there is some independent factor that causes both insulin resistance and these other effects. Detailed evaluation of patients with different sorts of severe insulin resistance has recently shed light on this matter. Fatty liver is a component of the common metabolic syndrome and a ubiquitous feature of lipodystrophy syndromes, and in both cases, it is strongly associated with high circulating TAG and low HDLcholesterol levels. This dyslipidaemic signature is extremely important because it is correlated with atherosclerosis risk and premature mortality (DeFronzo 2010). Recently published data from patients with severe insulin resistance due to lipodystrophy or the loss of function mutations in the insulin receptor gene itself (INSR) suggest that metabolic dyslipidaemia is due in part to increased hepatic lipogenesis driven by hyperinsulinaemia. This also appears to be true in obese patients with fatty liver (Donnelly et al. 2005) and in diabetic offspring (Petersen et al. 2007). After binding to the insulin receptor, insulin action is mediated by a complex, incompletely understood branching signalling network. The concept of partial or pathway-selective insulin resistance invokes the potential for insults to selectively inhibit only a subset of insulin's pleiotropic effects. Moreover, these defects might also be tissue selective, i.e. they might impair insulin action in different insulin target tissues to differing extents. This idea suggests that the hyperinsulinaemia associated with insulin resistance states could drive excess signalling via certain arms of the insulin-signalling network (with consequent hyperstimulation of some pathways), whereas signalling via other pathways might be clearly reduced. Evidence from murine studies suggests that fatty liver is typically associated with impaired insulin-stimulated suppression of hepatic gluconeogenesis, leading to the failure of insulin to suppress hepatic glucose output - the most 'traditional' definition of hepatic insulin resistance (resistance to insulin's glucose lowering 
actions) - but enhanced insulin-stimulated lipogenesis. Specifically, the canonical insulin signalling pathway through insulin receptor substrate 1 (IRS1), phosphoinositide 3-kinase $(\mathrm{PI} 3 \mathrm{~K})$, protein kinase $\mathrm{B}$ (AKT) and FoxO1 is downregulated, but a parallel pathway in which insulin receptor activation leads to up-regulation of the lipogenic transcription factor SREBP1c (known to be a key mediator of hepatic lipogenesis) is intact, thus mediating increased hepatic lipogenesis in the presence of hyperinsulinaemia. A study of 41 patients with severe insulin resistance due to insulin receptor abnormalities (congenital or acquired) compared to 13 patients with lipodystrophy and 42 patients with undefined molecular pathology showed an extreme form of the prevalent metabolic dyslipidaemia in the latter two groups but an apparently normal lipid profile in patients with INSR mutations in spite of high insulin and glucose levels and very modestly elevated free fatty acid levels. De novo hepatic lipogenesis and liver fat content were significantly increased in lipodystrophic patients, whereas they were within normal limits in patients with INSR mutations (Semple et al. 2009).

These data suggest that 'regular' obese insulin-resistant patients with fatty liver associated with increased hepatic lipogenesis have a post-receptor defect in insulin action. This is probably a unifying theme in insulin resistance. For example, it has been proposed that thecal cell proliferation in PCOS reflects preserved mitogenic (mitogen-activated protein kinase, or MAPK) signalling in the face of resistance to the glucose-lowering effect of insulin, largely mediated through the PI3K/AKT pathway. Moreover, the idea of partial insulin resistance is consistent with the clinical observation of pseudoacromegaly, a state characterised by acromegaloid features in the absence of excess $\mathrm{GH}$, in at least some patients with severe insulin resistance (Flier et al. 1993, Dib et al. 1998).

\section{Conclusions}

The identification and evaluation of patients with rare syndromes of congenital lipodystrophy are not only crucial to their clinical management, but also yields biological insights whose value is disproportionate to their prevalence. As described herein, the study of the molecular genetics of lipodystrophy has identified some of the key players in adipose tissue development and function. Given that a subset of lipodystrophy patients still lack a genetic diagnosis, these existing components are essential but not necessarily sufficient, and it is probable that novel lipodystrophy genes will be identified in the near future. Moreover, the study of patients with lipodystrophy has provided unique insights into the role of adipose tissue in human health, and has in particular contributed to a dramatic shift in the perception of adipose tissue as an essential component of metabolic homeostasis whose dysfunction, as with other tissues, greatly increases the risk of morbidity.
Together with other syndromes of severe insulin resistance (Semple et al. 2010), lipodystrophy has started to facilitate the dissection of the molecular mechanisms underlying the complications associated with insulin resistance. More generally, the study of patients with any monogenic disease can provide insights that are highly relevant to common human disease and which are very often unavailable from other models (in vitro or in vivo). In the case of lipodystrophy, the yields have been threefold: first, improved treatment strategies for patients; second, a greater understanding of adipose biology; and third, insights into the mechanism of a hugely prevalent phenotype that may one day enable us to combat it more effectively.

\section{Declaration of interest}

The authors declare that there is no conflict of interest that could be perceived as prejudicing the impartiality of the research reported.

\section{Funding}

Our work is supported by research grants from the Wellcome Trust (S O, Programme Grant 078986/Z/06/Z), GlaxoSmithKline (D B S), the Sackler Fund for Medical Science (I H-D), the Medical Research Council (J J R), the UK National Institute for Health Research Cambridge Biomedical Research Centre and the UK Medical Research Council Centre for Obesity and Related Metabolic Disease.

\section{Acknowledgements}

We are very grateful to many patients who while enduring considerable morbidity as a result of their disease have generously contributed to research studies aimed at advancing understanding of severe insulin resistance and lipodystrophy; and to their physicians for referring the patients to us.

\section{References}

Agarwal AK \& Garg A 2004 Seipin: a mysterious protein. Trends in Molecular Medicine 10 440-444. (doi:10.1016/j.molmed.2004.07.009)

Agarwal AK, Arioglu E, De Almeida S, Akkoc N, Taylor SI, Bowcock AM, Barnes RI \& Garg A 2002 AGPAT2 is mutated in congenital generalized lipodystrophy linked to chromosome 9q34. Nature Genetics 31 21-23. (doi:10.1038/ng880)

Agarwal AK, Fryns JP, Auchus RJ \& Garg A 2003 Zinc metalloproteinase, ZMPSTE24, is mutated in mandibuloacral dysplasia. Human Molecular Genetics 12 1995-2001. (doi:10.1093/hmg/ddg213)

Agostini M, Schoenmakers E, Mitchell C, Szatmari I, Savage D, Smith A, Rajanayagam O, Semple R, Luan J, Bath L et al. 2006 Non-DNA binding, dominant-negative, human PPARgamma mutations cause lipodystrophic insulin resistance. Cell Metabolism 4 303-311. (doi:10.1016/ j.cmet.2006.09.003)

Antuna-Puente B, Boutet E, Vigouroux C, Lascols O, Slama L, CaronDebarle M, Khallouf E, Lévy-Marchal C, Capeau J, Bastard JP \& Magré J 2010 Higher adiponectin levels in patients with Berardinelli-Seip congenital lipodystrophy due to seipin as compared with 1-acylglycerol-3phosphate-o-acyltransferase-2 deficiency. Journal of Clinical Endocrinology and Metabolism 95 1463-1468. (doi:10.1210/jc.2009-1824)

Bluher M 2009 The distinction of metabolically 'healthy' from 'unhealthy' obese individuals. Current Opinion in Lipidology 21 38-43. (doi:10.1097/ MOL.0b013e3283346ccc) 
Boguslavsky RL, Stewart CL \& Worman HJ 2006 Nuclear lamin A inhibits adipocyte differentiation: implications for Dunnigan-type familial partial lipodystrophy. Human Molecular Genetics 15 653-663. (doi:10.1093/hmg/ ddi480)

Boutet E, El Mourabit H, Prot M, Nemani M, Khallouf E, Colard O, Maurice M, Durand-Schneider AM, Chretien Y, Gres S et al. 2009 Seipin deficiency alters fatty acid Delta9 desaturation and lipid droplet formation in Berardinelli-Seip congenital lipodystrophy. Biochimie 91 796-803. (doi:10. 1016/j.biochi.2009.01.011)

Cao H \& Hegele RA 2000 Nuclear lamin A/C R482Q mutation in canadian kindreds with Dunnigan-type familial partial lipodystrophy. Human Molecular Genetics 9 109-112. (doi:10.1093/hmg/9.1.109)

Cao H, Alston L, Ruschman J \& Hegele RA 2008 Heterozygous CAV1 frameshift mutations (MIM 601047) in patients with atypical partial lipodystrophy and hypertriglyceridemia. Lipids in Health and Disease 73. (doi:10.1186/1476-511X-7-3)

Capanni C, Cenni V, Mattioli E, Sabatelli P, Ognibene A, Columbaro M, Parnaik VK, Wehnert M, Maraldi NM, Squarzoni S et al. 2003 Failure of lamin A/C to functionally assemble in R482L mutated familial partial lipodystrophy fibroblasts: altered intermolecular interaction with emerin and implications for gene transcription. Experimental Cell Research 291 122-134. (doi:10.1016/S0014-4827(03)00395-1)

Capanni C, Mattioli E, Columbaro M, Lucarelli E, Parnaik VK, Novelli G, Wehnert M, Cenni V, Maraldi NM, Squarzoni S et al. 2005 Altered pre-lamin A processing is a common mechanism leading to lipodystrophy. Human Molecular Genetics 14 1489-1502. (doi:10.1093/hmg/ ddi158)

Chong AY, Lupsa BC, Cochran EK \& Gorden P 2009 Efficacy of leptin therapy in the different forms of human lipodystrophy. Diabetologia $\mathbf{5 3}$ 27-35. (doi:10.1007/s00125-009-1502-9)

Cohen AW, Combs TP, Scherer PE \& Lisanti MP 2003 Role of caveolin and caveolae in insulin signaling and diabetes. American Journal of Physiology. Endocrinology and Metabolism 285 E1151-E1160. (doi:10.1152/ajpendo. $00324.2003)$

Colombo C, Cutson JJ, Yamauchi T, Vinson C, Kadowaki T, Gavrilova O \& Reitman ML 2002 Transplantation of adipose tissue lacking leptin is unable to reverse the metabolic abnormalities associated with lipoatrophy. Diabetes 51 2727-2733. (doi:10.2337/diabetes.51.9.2727)

Danforth E Jr 2000 Failure of adipocyte differentiation causes type II diabetes mellitus? Nature Genetics 26 13. (doi:10.1038/79111)

Dechat T, Pfleghaar K, Sengupta K, Shimi T, Shumaker DK, Solimando L \& Goldman RD 2008 Nuclear lamins: major factors in the structural organization and function of the nucleus and chromatin. Genes and Development 22 832-853. (doi:10.1101/gad.1652708)

DeFronzo RA 2010 Insulin resistance, lipotoxicity, type 2 diabetes and atherosclerosis: the missing links. The Claude Bernard Lecture 2009. Diabetologia 53 1270-1287. (doi:10.1007/s00125-010-1684-1)

Desvergne B \& Wahli W 1999 Peroxisome proliferator-activated receptors: nuclear control of metabolism. Endocrine Reviews 20 649-688. (doi:10. $1210 /$ er.20.5.649)

Dib K, Whitehead JP, Humphreys PJ, Soos MA, Baynes KC, Kumar S, Harvey T \& O'Rahilly S 1998 Impaired activation of phosphoinositide 3-kinase by insulin in fibroblasts from patients with severe insulin resistance and pseudoacromegaly. A disorder characterized by selective postreceptor insulin resistance. Journal of Clinical Investigation 101 1111-1120. (doi:10. 1172/JCI119884)

Donnelly KL, Smith CI, Schwarzenberg SJ, Jessurun J, Boldt MD \& Parks EJ 2005 Sources of fatty acids stored in liver and secreted via lipoproteins in patients with nonalcoholic fatty liver disease. Journal of Clinical Investigation 115 1343-1351. (doi:10.1172/JCI23621)

Erion DM \& Shulman GI 2010 Diacylglycerol-mediated insulin resistance. Nature Medicine 16 400-402. (doi:10.1038/nm0410-400)

Fei W, Shui G, Gaeta B, Du X, Kuerschner L, Li P, Brown AJ, Wenk MR, Parton RG \& Yang H 2008 Fld1p, a functional homologue of human seipin, regulates the size of lipid droplets in yeast. Journal of Cell Biology 180 473-482. (doi:10.1083/jcb.200711136) de Ferranti S \& Mozaffarian D 2008 The perfect storm: obesity, adipocyte dysfunction, and metabolic consequences. Clinical Chemistry 54 945-955. (doi:10.1373/clinchem.2007.100156)

Flier JS, Moller DE, Moses AC, O'Rahilly S, Chaiken RL, Grigorescu F, Elahi D, Kahn BB, Weinreb JE \& Eastman R 1993 Insulin-mediated pseudoacromegaly: clinical and biochemical characterization of a syndrome of selective insulin resistance. Journal of Clinical Endocrinology and Metabolism 76 1533-1541. (doi:10.1210/jc.76.6.1533)

Frayn KN 2002 Adipose tissue as a buffer for daily lipid flux. Diabetologia $\mathbf{4 5}$ 1201-1210. (doi:10.1007/s00125-002-0873-y)

Gale SE, Frolov A, Han X, Bickel PE, Cao L, Bowcock A, Schaffer JE \& Ory DS 2006 A regulatory role for 1-acylglycerol-3-phosphate-Oacyltransferase 2 in adipocyte differentiation. Journal of Biological Chemistry 281 11082-11089. (doi:10.1074/jbc.M509612200)

Garg A 2004 Acquired and inherited lipodystrophies. New England Journal of Medicine 350 1220-1234. (doi:10.1056/NEJMra025261)

Garg A, Fleckenstein JL, Peshock RM \& Grundy SM 1992 Peculiar distribution of adipose tissue in patients with congenital generalized lipodystrophy. Journal of Clinical Endocrinology and Metabolism 75 358-361. (doi:10.1210/jc.75.2.358)

Garg A, Peshock RM \& Fleckenstein JL 1999 Adipose tissue distribution pattern in patients with familial partial lipodystrophy (Dunnigan variety). Journal of Clinical Endocrinology and Metabolism 84 170-174. (doi:10.1210/jc. 84.1.170)

Gavrilova O, Marcus-Samuels B, Graham D, Kim JK, Shulman GI, Castle AL, Vinson C, Eckhaus M \& Reitman ML 2000 Surgical implantation of adipose tissue reverses diabetes in lipoatrophic mice. Journal of Clinical Investigation 105 271-278. (doi:10.1172/JCI7901)

George S, Rochford JJ, Wolfrum C, Gray SL, Schinner S, Wilson JC, Soos MA, Murgatroyd PR, Williams RM, Acerini CL et al. 2004 A family with severe insulin resistance and diabetes due to a mutation in AKT2. Science 304 1325-1328. (doi:10.1126/science.1096706)

Gesta S, Bluher M, Yamamoto Y, Norris AW, Berndt J, Kralisch S, Boucher J, Lewis C \& Kahn CR 2006 Evidence for a role of developmental genes in the origin of obesity and body fat distribution. PNAS 103 6676-6681. (doi:10.1073/pnas.0601752103)

Gray SL, Nora ED, Grosse J, Manieri M, Stoeger T, Medina-Gomez G, Burling K, Wattler S, Russ A, Yeo GS et al. 2006 Leptin deficiency unmasks the deleterious effects of impaired peroxisome proliferator-activated receptor gamma function (P465L PPARgamma) in mice. Diabetes 55 2669-2677. (doi:10.2337/db06-0389)

Haque W, Garg A \& Agarwal AK 2005 Enzymatic activity of naturally occurring 1-acylglycerol-3-phosphate-O-acyltransferase 2 mutants associated with congenital generalized lipodystrophy. Biochemical and Biophysical Research Communications 327 446-453. (doi:10.1016/j.bbrc.2004.12.024)

Hayashi YK, Matsuda C, Ogawa M, Goto K, Tominaga K, Mitsuhashi S, Park YE, Nonaka I, Hino-Fukuyo N, Haginoya K et al. 2009 Human PTRF mutations cause secondary deficiency of caveolins resulting in muscular dystrophy with generalized lipodystrophy. Journal of Clinical Investigation 119 2623-2633. (doi:10.1172/JCI38660)

Hill MM, Bastiani M, Luetterforst R, Kirkham M, Kirkham A, Nixon SJ, Walser P, Abankwa D, Oorschot VM, Martin S et al. 2008 PTRF-Cavin, a conserved cytoplasmic protein required for caveola formation and function. Cell 132 113-124. (doi:10.1016/j.cell.2007.11.042)

Kershaw EE \& Flier JS 2004 Adipose tissue as an endocrine organ. Journal of Clinical Endocrinology and Metabolism 89 2548-2556. (doi:10.1210/ jc.2004-0395)

Kim JB \& Spiegelman BM 1996 ADD1/SREBP1 promotes adipocyte differentiation and gene expression linked to fatty acid metabolism. Genes and Development 10 1096-1107. (doi:10.1101/gad.10.9.1096)

Kim JK, Fillmore JJ, Gavrilova O, Chao L, Higashimori T, Choi H, Kim HJ, Yu C, Chen Y, Qu X et al. 2003 Differential effects of rosiglitazone on skeletal muscle and liver insulin resistance in A-ZIP/F-1 fatless mice. Diabetes 52 1311-1318. (doi:10.2337/diabetes.52.6.1311)

Kim JY, van de Wall E, Laplante M, Azzara A, Trujillo ME, Hofmann SM, Schraw T, Durand JL, Li H, Li G et al. 2007 Obesity-associated improvements in metabolic profile through expansion of adipose tissue. Journal of Clinical Investigation 117 2621-2637. (doi:10.1172/JCI31021) 
Kim CA, Delepine M, Boutet E, El Mourabit H, Le Lay S, Meier M, Nemani M, Bridel E, Leite CC, Bertola DR et al. 2008 Association of a homozygous nonsense caveolin-1 mutation with Berardinelli-Seip congenital lipodystrophy. Journal of Clinical Endocrinology and Metabolism 93 1129-1134. (doi:10.1210/jc.2007-1328)

Koutkia P, Schurgin S, Berry J, Breu J, Lee BS, Klibanski A \& Grinspoon S 2005 Reciprocal changes in endogenous ghrelin and growth hormone during fasting in healthy women. American Journal of Physiology. Endocrinology and Metabolism 289 E814-E822. (doi:10.1152/ajpendo.00093. 2005)

Lane MD \& Tang QQ 2005 From multipotent stem cell to adipocyte. Birth Defects Research. Part A, Clinical and Molecular Teratology 73 476-477. (doi:10.1002/bdra.20150)

Liu L \& Pilch PF 2008 A critical role of cavin (polymerase I and transcript release factor) in caveolae formation and organization. Journal of Biological Chemistry 283 4314-4322. (doi:10.1074/jbc.M707890200)

Liu L, Brown D, McKee M, Lebrasseur NK, Yang D, Albrecht KH, Ravid K \& Pilch PF 2008 Deletion of Cavin/PTRF causes global loss of caveolae, dyslipidemia, and glucose intolerance. Cell Metabolism 8 310-317. (doi:10. 1016/j.cmet.2008.07.008)

Lloyd DJ, Trembath RC \& Shackleton S 2002 A novel interaction between lamin A and SREBP1: implications for partial lipodystrophy and other laminopathies. Human Molecular Genetics 11 769-777. (doi:10.1093/hmg/ 11.7.769)

Magre J, Delepine M, Khallouf E, Gedde-Dahl T Jr, Van Maldergem L, Sobel E, Papp J, Meier M, Megarbane A, Bachy A et al. 2001 Identification of the gene altered in Berardinelli-Seip congenital lipodystrophy on chromosome 11q13. Nature Genetics 28 365-370. (doi:10.1038/ng585)

Misra A \& Garg A 2003 Clinical features and metabolic derangements in acquired generalized lipodystrophy: case reports and review of the literature. Medicine 82 129-146. (doi:10.1097/00005792-20030300000007)

Misra A, Peethambaram A \& Garg A 2004 Clinical features and metabolic and autoimmune derangements in acquired partial lipodystrophy: report of 35 cases and review of the literature. Medicine 83 18-34. (doi:10.1097/01.md. $0000111061.69212 .59)$

Moitra J, Mason MM, Olive M, Krylov D, Gavrilova O, Marcus-Samuels B, Feigenbaum L, Lee E, Aoyama T, Eckhaus M et al. 1998 Life without white fat: a transgenic mouse. Genes and Development 12 3168-3181. (doi:10. $1101 /$ gad.12.20.3168)

Nishino N, Tamori Y, Tateya S, Kawaguchi T, Shibakusa T, Mizunoya W, Inoue K, Kitazawa R, Kitazawa S, Matsuki Y et al. 2008 FSP27 contributes to efficient energy storage in murine white adipocytes by promoting the formation of unilocular lipid droplets. Journal of Clinical Investigation 118 2808-2821. (doi:10.1172/JCI34090)

Payne VA, Grimsey N, Tuthill A, Virtue S, Gray SL, Dalla Nora E, Semple RK, O'Rahilly S \& Rochford JJ 2008 The human lipodystrophy gene BSCL2/seipin may be essential for normal adipocyte differentiation. Diabetes 57 2055-2060. (doi:10.2337/db08-0184)

Petersen KF, Dufour S, Savage DB, Bilz S, Solomon G, Yonemitsu S, Cline GW, Befroy D, Zemany L, Kahn BB et al. 2007 The role of skeletal muscle insulin resistance in the pathogenesis of the metabolic syndrome. PNAS 104 12587-12594. (doi:10.1073/pnas.0705408104)

Poitout V \& Robertson RP 2008 Glucolipotoxicity: fuel excess and beta-cell dysfunction. Endocrine Reviews 29 351-366. (doi:10.1210/er.2007-0023)

Puri V, Konda S, Ranjit S, Aouadi M, Chawla A, Chouinard M, Chakladar A \& Czech MP 2007 Fat-specific protein 27, a novel lipid droplet protein that enhances triglyceride storage. Journal of Biological Chemistry 282 34213-34218. (doi:10.1074/jbc.M707404200)

Robbins DC, Danforth E Jr, Horton ES, Burse RL, Goldman RF \& Sims EA 1979 The effect of diet on thermogenesis in acquired lipodystrophy. Metabolism 28 908-916. (doi:10.1016/0026-0495(79)90090-8)

Rosen ED, Walkey CJ, Puigserver P \& Spiegelman BM 2000 Transcriptional regulation of adipogenesis. Genes and Development 14 1293-1307. (doi:10. 1101/gad.14.11.1293)

Rubio-Cabezas O, Puri V, Murano I, Saudek V, Semple RK, Dash S, Hyden CS, Bottomley W, Vigouroux C, Magre J et al. 2009 Partial lipodystrophy and insulin resistant diabetes in a patient with a homozygous nonsense mutation in CIDEC. EMBO Molecular Medicine 1 280-287. (doi:10.1002/ emmm.200900037)

Saltiel AR \& Kahn CR 2001 Insulin signalling and the regulation of glucose and lipid metabolism. Nature 414 799-806. (doi:10.1038/414799a)

Saltiel AR \& Pessin JE 2003 Insulin signaling in microdomains of the plasma membrane. Traffic 4 711-716. (doi:10.1034/j.1600-0854.2003.00119.x)

Samuel VT, Petersen KF \& Shulman GI 2010 Lipid-induced insulin resistance: unravelling the mechanism. Lancet 375 2267-2277. (doi:10.1016/S01406736(10)60408-4)

Savage DB, Tan GD, Acerini CL, Jebb SA, Agostini M, Gurnell M, Williams RL, Umpleby AM, Thomas EL, Bell JD et al. 2003 Human metabolic syndrome resulting from dominant-negative mutations in the nuclear receptor peroxisome proliferator-activated receptor-gamma. Diabetes $\mathbf{5 2}$ 910-917. (doi:10.2337/diabetes.52.4.910)

Savage DB, Petersen KF \& Shulman GI 2007a Disordered lipid metabolism and the pathogenesis of insulin resistance. Physiological Reviews 87 507-520. (doi:10.1152/physrev.00024.2006)

Savage DB, Semple RK, Chatterjee VK, Wales JK, Ross RJ \& O'Rahilly S 2007 b A clinical approach to severe insulin resistance. Endocrine Development 11 122-132. (doi:10.1159/000111067)

Savage DB, Semple RK, Clatworthy MR, Lyons PA, Morgan BP, Cochran EK, Gorden P, Raymond-Barker P, Murgatroyd PR, Adams C et al. 2009 Complement abnormalities in acquired lipodystrophy revisited. Journal of Clinical Endocrinology and Metabolism 94 10-16. (doi:10.1210/jc.2008-1703)

Schlegel A, Volonte D, Engelman JA, Galbiati F, Mehta P, Zhang XL, Scherer PE \& Lisanti MP 1998 Crowded little caves: structure and function of caveolae. Cellular Signalling 10 457-463. (doi:10.1016/S0898-6568(98)00007-2)

Seip M \& Trygstad O 1996 Generalized lipodystrophy, congenital and acquired (lipoatrophy). Acta Paediatric. Supplementum 413 2-28. (doi:10. 1111/j.1651-2227.1996.tb14262.x)

Semple RK, Soos MA, Luan J, Mitchell CS, Wilson JC, Gurnell M, Cochran EK, Gorden P, Chatterjee VK, Wareham NJ et al. 2006 Elevated plasma adiponectin in humans with genetically defective insulin receptors. Journal of Clinical Endocrinology and Metabolism 91 3219-3223. (doi:10.1210/ jc.2006-0166)

Semple RK, Halberg NH, Burling K, Soos MA, Schraw T, Luan J, Cochran EK, Dunger DB, Wareham NJ, Scherer PE et al. 2007 Paradoxical elevation of high-molecular weight adiponectin in acquired extreme insulin resistance due to insulin receptor antibodies. Diabetes 56 1712-1717. (doi:10.2337/db06-1665)

Semple RK, Cochran EK, Soos MA, Burling KA, Savage DB, Gorden P \& O'Rahilly S 2008 Plasma adiponectin as a marker of insulin receptor dysfunction: clinical utility in severe insulin resistance. Diabetes Care 31 977-979. (doi:10.2337/dc07-2194)

Semple RK, Sleigh A, Murgatroyd PR, Adams CA, Bluck L, Jackson S, Vottero A, Kanabar D, Charlton-Menys V, Durrington P et al. 2009 Postreceptor insulin resistance contributes to human dyslipidemia and hepatic steatosis. Journal of Clinical Investigation 119 315-322. (doi:10.1172/ JCI37432)

Semple RK, Savage DB, Halsall DJ \& O'Rahilly S 2010 Syndromes of severe insulin resistance and/or lipodystrophy. In Genetic Diagnosis of Endocrine Disorders, Eds RE Weiss \& S Refetoff. London: Elsevier.

Sennello JA, Fayad R, Pini M, Gove ME \& Fantuzzi G 2006 Transplantation of wild-type white adipose tissue normalizes metabolic, immune and inflammatory alterations in leptin-deficient ob/ob mice. Cytokine 36 261-266. (doi:10.1016/j.cyto.2007.02.001)

Shackleton S, Lloyd DJ, Jackson SN, Evans R, Niermeijer MF, Singh BM, Schmidt H, Brabant G, Kumar S, Durrington PN et al. 2000 LMNA, encoding lamin A/C, is mutated in partial lipodystrophy. Nature Genetics 24 153-156. (doi:10.1038/72807)

Simha V \& Garg A 2003 Phenotypic heterogeneity in body fat distribution in patients with congenital generalized lipodystrophy caused by mutations in the AGPAT2 or seipin genes. Journal of Clinical Endocrinology and Metabolism 88 5433-5437. (doi:10.1210/jc.2003-030835)

Sissons JG, West RJ, Fallows J, Williams DG, Boucher BJ, Amos N \& Peters DK 1976 The complement abnormalities of lipodystrophy. New England Journal of Medicine 294 461-465. (doi:10.1056/NEJM197602262940902) 
Snijder MB, Zimmet PZ, Visser M, Dekker JM, Seidell JC \& Shaw JE 2004 Independent and opposite associations of waist and hip circumferences with diabetes, hypertension and dyslipidemia: the AusDiab Study. International Journal of Obesity and Related Metabolic Disorders 28 402-409. (doi:10.1038/ sj.ijo.0802567)

Spalding KL, Arner E, Westermark PO, Bernard S, Buchholz BA, Bergmann O, Blomqvist L, Hoffstedt J, Naslund E, Britton T et al. 2008 Dynamics of fat cell turnover in humans. Nature 453 783-787. (doi:10.1038/ nature06902)

Speckman RA, Garg A, Du F, Bennett L, Veile R, Arioglu E, Taylor SI, Lovett M \& Bowcock AM 2000 Mutational and haplotype analyses of families with familial partial lipodystrophy (Dunnigan variety) reveal recurrent missense mutations in the globular C-terminal domain of lamin A/C. American Journal of Human Genetics 66 1192-1198. (doi:10.1086/302836)

Spiegelman BM 1998 PPAR-gamma: adipogenic regulator and thiazolidinedione receptor. Diabetes 47 507-514. (doi:10.2337/diabetes.47.4.507)

Szymanski KM, Binns D, Bartz R, Grishin NV, Li WP, Agarwal AK, Garg A, Anderson RG \& Goodman JM 2007 The lipodystrophy protein seipin is found at endoplasmic reticulum lipid droplet junctions and is important for droplet morphology. PNAS 104 20890-20895. (doi:10.1073/pnas. 0704154104)

Tan GD, Savage DB, Fielding BA, Collins J, Hodson L, Humphreys SM, O'Rahilly S, Chatterjee K, Frayn KN \& Karpe F 2008 Fatty acid metabolism in patients with PPARgamma mutations. Journal of Clinical Endocrinology and Metabolism 93 4462-4470. (doi:10.1210/jc.2007-2356)
Tershakovec AM, Frank I \& Rader D 2004 HIV-related lipodystrophy and related factors. Atherosclerosis 174 1-10. (doi:10.1016/S0021-9150(03) 00246-6)

Tran TT, Yamamoto Y, Gesta S \& Kahn CR 2008 Beneficial effects of subcutaneous fat transplantation on metabolism. Cell Metabolism 7 410-420. (doi:10.1016/j.cmet.2008.04.004)

Virtue S \& Vidal-Puig A 2008 It's not how fat you are, it's what you do with it that counts. PLoS Biology 6 e237. (doi:10.1371/journal.pbio.0060237)

Williams DG 1997 C3 nephritic factor and mesangiocapillary glomerulonephritis. Pediatric Nephrology 11 96-98. (doi:10.1007/s004670050241)

Wojtanik KM, Edgemon K, Viswanadha S, Lindsey B, Haluzik M, Chen W, Poy G, Reitman M \& Londos C 2009 The role of LMNA in adipose: a novel mouse model of lipodystrophy based on the Dunnigan-type familial partial lipodystrophy mutation. Journal of Lipid Research 50 1068-1079. (doi:10.1194/jlr.M800491-JLR200)

Worman HJ \& Bonne G 2007 "Laminopathies": a wide spectrum of human diseases. Experimental Cell Research 313 2121-2133. (doi:10.1016/j.yexcr. 2007.03.028)

Received in final form 13 September 2010

Accepted 24 September 2010 Made available online as an Accepted Preprint 24 September 2010 